\title{
A Formação da Elite Jurídica no Rio Grande do Sul:
}

\section{Notas para uma Pesquisa}

\author{
Fabiano Engelmann
}

Bacharel em Direito UFRGS, Mestrando em Ciência Política UFRGS

\section{Introdução}

\begin{tabular}{|c|} 
SUMÁRIO \\
\hline Introdução; \\
1. Referencial teórico; \\
2. Problema; \\
2.1 Elementos para o estudo da for- \\
mação da elite jurídica no Brasil: contex- \\
to e recursos analíticos; \\
2.2 Recursos Analíticos e Indicadores; \\
2.3 Estudo do Caso Específico; \\
3. Alguns resultados parciais e questões \\
metodológicas; \\
4. Bibliografia consultada.
\end{tabular}

(1)

te artigo foi redigido a partir do texto de um projeto de dissertação de mestrado em ciência política e pretende expor o problema de pesquisa formulado, bem como, apresentar alguns resultados parciais da investigação que encontra-se em andamento. Tal pesquisa situa-se na temática da formação e recrutamento de elites e tem por objetivo o estudo específico da composição social, trajetórias e padrões de homogeneização que intervém na estruturação da elite jurídica no Rio Grande do Sul. A base empírica do estudo compreende o corpo docente e discente associados à trajetória da Faculdade Livre de Direito de Porto Alegre/UFRGS.

A presença do bacharel em direito como mediador social e político, em distintos períodos históricos, tal como indicam os estudos de VENÂNCIO FILHO (1982) MICELI (1979), CARVALHO (1996) e ADORNO (1988), deve ser estudada considerando-se um conjunto de condicionantes 
que extrapolam a componente escolar da formação jurídica. Estas regularidades comportam a explicitação de variáveis que apontem para as representações comuns do social e do político, para as origens sociais e para a trajetória dos agentes individuais e grupos aos quais estes se vinculam.

Tendo tais elementos presentes, pretende-se analisar o caso específico a partir de referenciais da ciência política, sob um viés que se afaste das perspectivas dominantes da "sociologia do direito" incorporada à doxa jurídica como "teoria critica do direito". ${ }^{1}$ Tal postura implica em situar o objeto em construção dentro da problemática que permeia a formação do Estado no Brasil. Considera-se, pois, as estratégias de importação de modelos políticos e tecnologias institucionais e as ambivalências daí decorrentes, quanto a adaptação e uso destes modelos, bem como, a problemática da "profissionalização" e inserção dos juristas que operam estas tecnologias, nas diversas esferas sociais.

O recorte específico proposto, enfocando o conjunto do corpo docente e discente de egressos da Faculdade Livre de Direito de Porto Alegre/UFRGS justifica-

1. Nos meios jurídicos brasileiros a "sociologia do direito" está associada a uma visão "crítica" ou "social" do direito. Esta crítica é produzida numa apropriação "jurídica" de conceitos sociológicos, psicanalíticos, e semiológicos, predominando a matriz marxista. Tal "sociologia" afigura-se como tomada de posição ideológica nas lutas inter-pares no seio da elite jurídica, o que compromete seu potencial analitico, embora não seu conteúdo informativo. Pode-se encontrar algumas orientaçōes metodológicas para o estudo deste feñómeno em Dezalay (1989).

2. Uma das representaçóes desta crise pode ser lida no trabalho auto-intitulado de "sociologia do direito" de Arruda Jr. (1988) p. 96 : "...uma parte de 'crise' de identidade por qual atravessam, os jovens Bacharéis em direito no Brasil, e nos restringimos aos mais jovens, pois dos mais de 200.000 advogados brasileiros, cremos que 150.000 foram formados nos últimos 20 anos deve-se deliberada poltica educacional consentanea ao modelo economico do Estado pos-64 e ao autoritarismo que, espelhado no terror (grito meu). A escola e o Direito de hoje jamais poderá ser a escola de Direito liberal de outrora (grifo do autor). referenciais para o problema presente no caso específico a ser analisado. Num segundo momento, expor-se-á o problema de pesquisa e alguns resultados parciais resultantes do trabalho de indicadores nele levantados.

\section{Referencial teórico}

Um ponto de partida importante para o estudo da legitimação da competência técnica, social e política dos bacharéis, pode ser encontrado nos trabalhos de BOURDIEU (1986, 1989), LACROIX (1992) e CHARLE (1987). Ao estudar os padrões que estruturam as lógicas presentes na "instituição do monopólio de dizer o direito", fundamento da competência social dos juristas na França, BOURDIEU (1986) vai chamar a atenção, não somente para os elementos presentes na "ciência ju rídica" que conformam o espaço de possíveis de decisões e teorização mas principalmente, para a "homogeneidade dos habitus ${ }^{3}$ jurídicos". Esta homogeneidade é inscrita na relativa comunização das categorias de percepção e de apreciação que estruturam a percepção e a apreciação dos conflitos orientando o trabalho destinado a transformar-se em confrontações jurídicas.

Esta perspectiva conduz o autor a não considerar isoladamente, na decomposição dos mecanismos de homogeneização das percepções dos bacharéis, um saber apreendido no sistema de conceitos pre sentes na "ciência jurídica", ${ }^{4}$ mas relevar em máxima amplitude, o espaço social ${ }^{5} \mathrm{em}$ que estes agentes se movem.

Tendo em vista os esquemas de percepção comuns estabelecidos na afinidade de habitus, que relaciona a trajetória social do agente com sua formação e $o$ grupo social que ele produz e reproduz, pode-se buscar subsídios que permitam a apreensão da natureza destes esquemas. Dentro desta perspectiva, BOURDIEU vai explicitar os

3. A noção de habitus, nos termos desenvolvidos por Bourdieu (1989), permite apreender o "acordo imediato entre a estrutura cognitiva dos princípios de visão e divisão do mundo social" $\mathrm{e}$ as relaçōes entre as estruturas objetivas e as estruturas incorporadas pelos agentes. A afinidade de habitus é que, em última instância, vai garantir a homogeneização do grupo, onde a formação intelectual, no caso a formação jurídica, é apenas um fator agregado que formaliza a entrada em determinado corpo de especialistas.

4. As lutas e clivagens que se traduzem nas disputas entre concepç̋es de "ciência jurídica" sáo um indicador importante que, entretanto, deve ser investigado considerando-se as trajetorias e apostas dos agentes em luta num contexto determinado. A advertência justifica-se pela tendência, em vários diagnósticos ligados a "sociologia do direito" brasileira, a correlacionar meca. nicamente o tipo de formação juríicica com a trajetória do grupo de bacharéis tal como em Souto e Falcão (1980): "Uma das contribuiç̧es da sociologia do direito consiste em fornecer aos profissionais do direito um instrumental analítico, de base cientilfical que vai permitir o reencontro do nosso chamado sistema normativo com a nossa realidade social. Pois a distância que

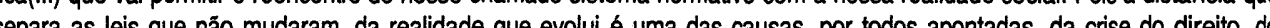
cepara as lois que no decisão nacional".

5. A descriçăo da sociedade em termos de espaço social permite acentuar a dimensão relacional das posiçōes sociais. Nestes termos, a posição dos agentes no espaço social é dada, por um lado, de acordo com o volume do capital possuído e, por outro lado, pela estrutura deste capital. A estrutura diferenciada de capitais permite opor agentes que possuem o mesmo volume de capital num eixo vertical, como por ex. o capital económico dos industriais $\theta$ o capital cultural dos professores universitários. Esta reflexão é desenvolvida em Bourdieu (1984)

Revista da Faculdade. de Direito da UFRGS, v. 17, 1999

Revista da Faculdade de Direito da UFRGS, v. 17, 1999 
mecanismos de hierarquização e homogeneização que constituem o $a$ priori dos profissionais do direito na França e permitem a diferenciação de um campo jurídico relativamente autônomo em relação a outras esferas sociais, conforme demonstra a seguir:

"As práticas e os discursos jurídicos são, com efeito, produto do funcionamento de um campo cuja lógica específica está duplamente determinada: por um lado, pelas relações de força específicas que lhe conferem a sua estrutura e que orientam as lutas de concorrência ou, mais precisamente, os conflitos de competência que nele têm lugar e, por outro lado, pela lógica interna da obras jurídicas que delimitam em cada momento o espaço dos possíveis e, deste modo, o universo das soluções propriamente jurídicas." (BOURDIEU 1985, p. 3)

A categoria de intérpretes autorizados, referida por BOURDIEU, tende a se distribuir em dois pólos extremos. De um lado, um conjunto de agentes voltados para a elaboração puramente teórica da doutrina, os professores, encarregados de ensinar, em forma formalizada e normalizada as regras em vigor e, de outro, os operadores do direito, ligados a interpretação e avaliação de casos particulares.

Aprofundando a reflexão sobre esta especialização das funções na estruturação da atuação dos profissionais do direito, LACROIX (1992), enfoca o processo de

formalização jurídica, na atuação dos especialistas em direito e suas diversas trajetórias sociais, visto que, no exercício destas especialidades é que se permite verificar as diferenças intrínsecas que separam os usos sociais ${ }^{6}$ bastante diversos dos saberes jurídicos. Um dos exemplos dados, em seu trabalho, concerne ao uso do direito como forma de justificar ações políticas (conforme a "regra") ligado ao aparecimento da atividade do constitucionalista. Neste caso, a ligação do professor de direito constitucional com a "vida política" se funda na legitimidade de sua competência técnica de interpretar e dizer se determinada ação política enquadra-se na regra de direito.

Para o autor, considerar a especialização profissional significa superar a análise da formação inicial idêntica que dá direito de entrada no campo das profissões jurídicas, buscando estudar suas diferenciações. Esta diversidade corresponde aos usos sociais distintos dos produtos jurídicos praticados pelos atores sociais em lutas específicas.

O referencial empírico desta abordagem, que situa na diferenciação profissional e na manipulação autorizada de uma competência técnica, variáveis importantes para a compreensão do poder social dos juristas, é produto do contexto francês onde ocorre a separação entre a competência técnica dos agentes que operam a doutrina jurídica e a competência doutrinária dos agentes que produzem o conhecimento te-

6. Estes "usos sociais" podem ser compreendidos como os processos $\theta$ as logicas práticas responsáveis pela apariçăo de formas práticas e simbolicas de ação e de organizaçăo coletivas (Lacroix, 1986). No caso do direito, manifesta-se nas lutas interagentes, na invençăo e vulgarizaçăo "singular" de formas jurídicas de percepçáo do social.

Revista da Faculdade de Direito da UFRGS, v. 17, 1999 órico tal como assinalado por BOURDIEU (1996). Da mesma forma, pressupõe o re conhecimento do jurista como detentor de uma competência derivada de um saber es colar vinculado a padrões meritocráticos, impessoais e burocráticos, intrínsecos à profissão de jurista. A transposição desta análise para o caso brasileiro adquire maior complexidade, pois em não ocorrendo a diferenciação entre o "produtor" e o "aplicador" do direito, a produção das doutrinas ficará totalmente subordinada à "vida política", praticamente inexistindo um sa ber escolar que legitime a autonomização de um campo jurídico.

Tendo-se referido noções que tratam, numa dimensão mais abstrata, a compre ensão dos mecanismos de homogeneização do grupo social que se pretende investigar, procurar-se-á expor categorias analíticas e indicadores utilizados em estudos de recru tamentos de elites que permitam construir referenciais para o estudo da seleção dos componentes da elite jurídica.

Em estudo sobre recrutamento de elites burocráticas na França, no período de 1880-1900, CHARLE (1987) destaca, entre variáveis a serem relevadas visando a apreensão dos mecanismos de seleção soci al destas elites, as variáveis demográficas, culturais, ideológicas, dinâmicas (troca de atividade), financeiras e origens sociais. Correlacionada à origem social, a trajetória escolar aparece como central para a compreensão das lógicas que operam na ascensão e reprodução de posições de elite, tendo em vista, o contexto histórico de republicanização da França em que se insere o estudo.

O autor destaca que, em se tratando de elites jurídicas, há que se considerar conjugado às variáveis mencionadas, a trajetória do grupo familiar, visto que as profissões jurídicas geralmente encerram "uma cultura familiar com forte reprodução social". Um dos recursos analíticos capaz de explicitar as lógicas de reprodução desta herança social, onde o capital escolar opera parcialmente, é a noção de capital social e os mecanismos que operam este capital, conjugado a outros capitais, as reconversões. O capital social do agente pode ser entendido como o "conjunto de recursos atuais ou potenciais que são ligados à possessão de um recurso durável de relações mais ou menos institucionalizadas de interconhecimento e de interreconhecimento" (BOURDIEU, 1980). Esta forma de capital aparece no conjunto de reconversões que permite a apreensão da trajetória ${ }^{7}$ de um grupo social ou agente singular num determinado espaço social. Segundo SAINT MARTIN

7. A distinçăo entre o uso da noção de trajetoria em relação a noçăo de "historia de vida" é desenvolvida em Bourdieu (1986). Segundo o autor: "a trajetoria pode ser entendida como série de posiçōes sucessivamente ocupadas por um mesmo agente (ou " um mesmo grupo) em um espaço ele proprio em devir e submetido a incessantes transiormaçరes. Operando com esta noçāo no contexto brasileiro, Grynszpan (1990) chama a alençao para sos, as formas como os utilizam ou procuram maximizá-los, suas redes de relacoses, como se estruturam, como as acionam nelas se locomovem ou as abandonam". 
(1993), ${ }^{8}$ o estudo das reconversões permite analisar o processo de desvalorização e revalorização das diferentes espécies de capital.

Os aspectos concernentes à herança social serão relevados por CHARLE (1989) ao propor uma "história social das profissões jurídicas". O autor acentua que nas profissões jurídicas, em suas diversas especialidades, o capital social é mais facilmente reconvertido em outros tipos de capital, como capital econômico no caso dos notários e capital político no caso dos advogados assinalando que, no caso da França, a perenidade das profissões jurídicas que atravessam os séculos pode ser atribuída à capacidade de acumulação e reprodução do capital social coletivo conservado através de mecanismos institucionais.

No caso brasileiro, entretanto, a reprodução deste capital social coletivo não pode ser apreendida a partir de garantias institucionais, pois o acesso a estas garantias não está baseado em princípios de hierarquização profissionais. Na próxima parte tentar-se-á expor as diferenciações do contexto do caso a ser analisado visando discutir as possibilidades de utilização do referencial teórico descrito.

\section{Problema}

\subsection{Elementos para o estudo da \\ formação da elite jurídica no \\ Brasil: contexto e recursos} analíticos

A apreensão do caso específico a ser tratado implica na inclusão de outros níveis de análise aos trabalhados nas pesquisas referidas, frutos de contextos onde ocorre a objetivação de mecanismos que garantem a equivalência entre o título escolar e a posição social.

Diferenciadamente do contexto francês de predomínio dos padrões meritocráticos de seleção da elite burocrática e onde a profissão e a herança profissional tem um peso fundamental na sua reprodução, no Brasil operam lógicas distintas que podem ser captadas já na explicitação das estratégias de importação dos cursos jurídicos. A importação de tecnologias institucionais no período imperial orienta-se para a "formação do Estado Nacional" com a produção de uma elite capaz de "operacionalizá-lo". Logo, mesmo a "competência técnica" dos bacharéis fica $a$ priori subordinada a uma "missão política", como demonstra a citação que segue:

8. No caso da nobreza francesa, analisado por Saint-Martin (1993), as estratégias de reconversão dão lugar às separaç̄es (clivagens) no espaço social, com o abandono de posiçóes estáveis, desvalorizadas ou ameaçadas, por aqueles que as ocupam por longo to $m$, em la sucessoria, do

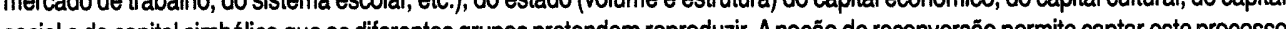
social e do captal simbol co quos diteron e, consequüentemente, correlacionar o conjunto de variáveis que envolvem o titulo escolar, a origem social, as apostas de carreira,

"Essa orientação que chamaríamos atualmente de teórica, enfatizava na formação de bacharel a percepção dos fundamentos últimos da vida social e politica (grifo meu). O Direito aparecia como $\mathrm{o}$ instrumento normatizador das relações políticas, sociais e econômicas. $\mathrm{O}$ bacharel formado deveria saber os princípios de Direito Público, Eclesiástico e Constitucional, pois a atenção central dos estudos deveria estar focalizada no entendimento e funcionamento do governo." (BARRETO, 1978, p. 207) ${ }^{9}$

Esta ligação à "vida social" e à "vida política", permite ao bacharel constituir-se como mediador, haja vista sua atuação simultânea em várias esferas, conforme assinala ADORNO (1988), outorgando-lhe aprioristicamente a vocação ${ }^{10}$ de elite dirigente. Tal peculiaridade circunda a apropriação e uso do "direito" no Brasil e destaca a variável da inserção da elite jurídica na vida política do País e o impacto desta presença na sua reprodução social.

Um dos estudos que considera esta inserção, no período imperial, é o de CARVALHO (1996). O autor destaca como os bacharéis em direito assumiram um papel central na unificação do Estado imperial atuando como elite homogênea. Um dos pressupostos garantidores desta homogeneização era a formação jurídica em
Coimbra. Entretanto, o autor atribui um peso excessivo à competência técnica do bacharel em sua ascensão social e política atribuindo ao título escolar o ponto de partida para esta ascensão. Tal visão diminui a participação de outros recursos na trajetória dos agentes tais como, o capital social e as redes de relações envolvendo o pertencimento a determinados grupos familiares e sociedades. O capital social e as redes de relaçóes entabuladas pelo agente ao longo de sua trajetória social são fundamentais em contextos de não-predomínio de princípios de hierarquização social baseados na profissão, conforme indicam estudos sobre elites políticas no período imperial. ${ }^{11}$

Para a construção de indicadores eficazes visando a apreensão desse fenômeno, deve-se contabilizar a importação de modelos jurídico-políticos e os usos sociais desta tecnologia de poder ${ }^{12}$ que permeiam as práticas sociais dos bacharéis, na medida em que, os modelos importados são apropriados como bens simbólicos sem a incorporação do ethos que lhes corresponde e associados a outros recursos sociais, subordinam-se à legitimação de uma competência política. Também importa relevar as posições ocupadas pelos agentes, na trajetória da elite jurídica, considerando suas propriedades sociais. No caso, a hierarquia

9. Esta passagem foi extraída de uma coletânea produzida por juristas que busca analisar as condicionantes do surgimento dos cursos jurídicos no Brasil, cujo marco histórico é atribuído à Constituinte de 1823.

10. A formação de uma "vocação para o poder" leva a necessidade de investigar-se as representaçäes comuns acerca do fenômeno político por parte dos bacharéis, tal como procede, em relação aos intelectuais no Brasil, Pécaut (1990).

11. Ver Coradini (1998)

12. Ver Bendix (1996) que demonstra comparativamente os processos sociais-políticos da Europa que originaram categorias como "cidadania", "Estado de Direito" e o ethos que lhes corresponde. Ver sobre a problemática da importação dos modelos políticos em contextos neopatrimoniais, Badie \& Hermet (1990).

Revista da Faculdade de Direito da UFRGS, v. 17, 1999 
destas posições é dada na relação entre os valores atribuídos a determinados recursos, sua posse por parte dos agentes e os princípios de hierarquização que estruturam o espaço de atuação dos mesmos.

\subsection{Recursos Analíticos}

e Indicadores

Dentro do quadro exposto, pode-se tentar construir referenciais que permitam apreender as lógicas e mecanismos que estruturam a trajetória e homogeneização da elite jurídica brasileira. ADORNO (1988), acentua o fato das escolas de direito criadas no período imperial não terem se constituído como centros de produção de um "direito brasileiro". Ao estudar a Academia de Direito de São Paulo, ${ }^{13}$ o autor constatou a forte presença do corpo docente e discente nas lutas sociais e políticas considerando os indicadores de participação na imprensa e grêmios literários e do exercício de cargos públicos. Ao confrontar estes indicadores com os referentes à produção intelectual e à atividade docente, o autor verificou a inexistência de uma lógica escolar no campo do direito.

Quanto aos mecanismos de ingresso na carreira universitária jurídica, refere o autor, a pessoalidade como regra nos procedimentos de recrutamento de professo- res e nas práticas avaliatórias dos alunos. Estes indicadores da atuação em diversas esferas, por parte do corpo docente e discente e dos mecanismos que operam em sua seleção e recrutamento, são fundamentais para a apreensão das lógicas que caracterizam as faculdades de direito brasileiras como espaços de socialização onde são reconvertidos diversas formas de capitais que entram em jogo na definição da ascensão e reprodução de posições de elite. Da mesma maneira, os dados trazidos por ADORNO não permitem atribuir ao título de bacharel o ponto de partida para a as. censão social e política. $O$ título escolar aparece, antes, como o "certificado de uma posição social e política de antemão ocupada", conforme CORADINI (1998). ${ }^{14}$

A formação de redes de relações, a partir de critérios pessoais, é característica da dinâmica descrita e expressa-se nas práticas do nepotismo, da patronagem e do clientelismo, fenômenos presentes na trajetória da elite burocrática brasileira. Desta forma, os recursos analíticos já expostos trabalhados em contextos onde as competências técnicas tem um peso significativo na hierarquização e reprodução das elites jurídicas, não são suficientes para a compreensão da dinâmica brasileira, onde a "pessoa total" encontra-se envolvida, na

13. As logicas de recrutamento que operam na produção e reprodução da elite jurídica, neste caso, permanecem e expandem-se com a "descentralizaçẫo" dos cursos juríicicos iniciada com o período republicano que redunda na criação de novas escolas por todo o País. Uma descrição detalhada quanto ao aspecto referente à expansáo do ensino jurídico e suas características pode ser encontrada em Venâncio Filho (1982).

14. Em estudo sobre o recrutamento da elite médica, no Brasil no período imperial, o autor constata que: "...a seleção da elite

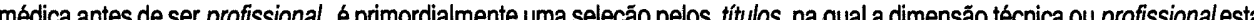
médica antes de ser profissional, é primordialmente uma seleçăa pelos tîulos, na qual a dimensáa técnica ou profissional está sempre subordinada à dimensão da notoriedade ou de títulos que atestam determinadas relaçóes (com o imperador e personagens do poder central, numa primeira fase; de pioneiro na introdução das inovaçóes em alguma especialidade ou de sua
representação, de homem público e moral, num segundo momento)". (Coradini 1998, p. 6)

Revista da Faculdade de Direito da UFRGS, v. 17, 1999 medida em que, não ocorre a objetivação de critérios formais típicos do que poder-se-ia considerar como um contexto republicano.

Para a apreensão destas redes de relações e o conjunto de fenômenos que pode ser genericamente caracterizado como relações de reciprocidade e que não perpassam apenas a estruturação e mobilidade da elite jurídica, mas o conjunto de relações que envolve o Estado brasileiro, pode-se recorrer a noções oriundas de estudos antropológicos, como as de "amizade instrumental", "quase grupos" e "relações diádicas", que podem ser usados complementarmente à noção de capital social. ${ }^{15}$

\subsection{Estudo do Caso Específico}

A Faculdade "Livre" de Direito de Porto Alegre, fundada em 1900, tem sua origem inserida na estratégia de produção de lideranças políticas no Estado, confor me indicam LEITE e FRANCO (1992) ${ }^{16}$ Segundo as autoras prevalece no curso de Direito uma cultura de "cumplicidade consensual" com o governo do Estado do Rio Grande do Sul, decorrente da estreita correspondência entre o exercício do poder e a "vida acadêmica" no interior desta. Tais fatores são descritos no texto de "história da Faculdade" produzido por BRAGA (1975) que, apesar de adotar uma perspectiva consagratória, traz informações que vão ao encontro dos dados coletados por ADORNO (1988).
A inserção do corpo docente e discente em diversas esferas sociais, destoante de uma lógica "profissional", também é acentuada por GRIJÓ (1998). Neste estudo, comparando as trajetórias dos integrantes da "geração de 1907", o autor, demonstra que as estratégias de importação e uso político de ideologias jurídicas e as clivagens no corpo docente e discente eram pautadas pela conjuntura política do período analisado, permitindo afirmar que lógicas que operam a "vida acadêmica" no interior da instituição estruturam-na como um grande labo. ratório onde refletem-se as lutas sociais e políticas do momento.

Partindo dos parâmetros estabelecidos, nestes estudos, pode-se investigar se subsistem, ou não, os padrões de estruturação e condicionamentos que originaram os cursos de Direito no Brasil no período imperial, na trajetória da elite jurídica gaúcha. Por outro lado, indaga-se em que medida a introdução formal de mecanismos auferidores de competências técnicas - como os concursos públicos para postos burocráticos, conjugados a indicadores de maior diversificação social, corporativização por especialidades (principalmente a partir da década de 30) e institucionalização do ensino jurídico -, implicam na alteração dos padrões de formação e recrutamento desta elite em direção a prevalência de padrões meritocráticos. ${ }^{17}$
15. Sobre a problemática teórica envolvendo o uso destas noçőes complementarmente à noção e capital social, ver Coradini (1995). Sobre as possibilidades de uso das noçoes de "quase grupos", "amizade instrumental" em sociedades complexas, ver Bianco (1987). Sobre a noçăo de "relaçōes diádicas" ver Landé (1977).

16. O estudo das autoras compreende o período de 1900-1936.

17. O trabalho de Miceli (1979) vai relevar esta mudança de padrōes de recrutamento considerando que na Primeira República o recrutamento dos intelectuais (no caso analisado em sua maioria bacharéis em direito) se realizava em função da rede de rela- 

cial.

Estudar estes padrões de seleção social implica em centrar o foco de análise nos recursos reconvertidos pelos bacharéis, sua trajetória social e o pertencimento a determinados grupos familiares e sociedades, tal como já pontuado. Este enfoque permite a verificação da ocorrência da transição do predomínio de uma "vocação política" para o predomínio de uma "vocação jurídica" no caso dos bacharéis gaúchos. Ou seja, de uma "escola" abertamente inserida nas lutas sociais e políticas para a aposta em uma competência técnica propriamente jurídica, cujo espaço estaria definido na corporativização das profissões jurídicas, e nos mecanismos de seleção daí advindos que comportariam, conseqüentemente, $o$ título escolar, a competência técnica e a meritocracia como trunfos de ascensão so-

Tendo-se, como hipótese de trabalho, a idéia da prevalência de um mecanismo de recrutamento meritocrático que imperaria com a construção das carreiras jurídicas aumentando o peso do título escolar, nossa proposta de pesquisa agrega a estes mecanismos os indicadores propriamente sociais estruturantes da "vocação para o direito". Logo, o problema consiste em explicitar a permanência da herança social e as estratégias de reprodução dos grupos e agentes, bem como, as reconversões operadas visando garantir suas posições de destaque na trajetória da elite jurídica gaúcha, que transpassa o fenômeno da inflação de diplomas, a diminuição

de seu capital simbólico e, por conseqüência, as representações da "crise do direito".

\section{Alguns resultados parciais e questões metodológicas}

A seguir procede-se a exposição de dados parciais da pesquisa concernentes a trajetória profissional/ocupacional do corpo docente da faculdade de Direito. Tais dados resultados da operação da pesquisa, envolvendo o corpo docente, deverão ser aprofundados tomando-se amostragens de professores para coleta de depoimentos. Procurar-se-á reconstruir a trajetória ocupacional/profissional de forma mais aprofundada, visando a comparação entre trajetórias e, conseqüentemente, a mensuração dos recursos sociais e escolares reconvertidos para a ascensão a posições de elite. Para a montagem dos dados a seguir privilegiou-se, na medida do possível, as informações concernentes aos indicadores de filiação, local de nascimento, ocupação do pai, ano de formatura, estudos escolares pré-universitários e universitários, carreira profissional, produção intelectual geral, produção intelectual técnica, participação e pertencimento a sociedades e clubes sociais/culturais e trajetória política. Tendo em vista a parcialidade dos dados produzidos, optou-se neste artigo somente por expor os dados referentes a trajetória ocupacional/profissional. Quanto a coleta de informações referentes ao corpo discente, proceder-se-á com os mesmos indicadores organizando-os por ano de forma-

çós sociais que estes mobilizavam, ao passo que no período "pos-30", a cooptaçăo das novas categorias de intelectuais por parte do Estado passaria a incorporar ao capital de relaçóes sociais, a mediaçăo exercida por trunfos escolares e culturais cujo peso é tanto maior quanto mais se acentua a concorrência no interior do campo intelectual. tura e trabalhando-se com amostragens por década a partir de 1960. A pesquisa comporta também o trabalho com fontes complementares como artigos, revistas, homenagens, discursos, atas e demais fontes presentes em múltiplos arquivos como os das associações corporativas. $\mathrm{O}$ detalhamento metodológico do tratamento destas fontes será omitido em função dos limites do artigo.

Analisando os resultados parciais tra zidos pela operacionalização desta investigação tomando-se por base as informações coligidas no trabalho de BRAGA (1975) e fontes subsidiárias, visualiza-se a presença dos professores da Faculdade de Direito na fundação de várias instituições de natureza cultural e intelectual. Destacam-se os professores de Direito como fundadores do Instituto Histórico Geográfico do Rio Grande do Sul, da Academia Rio-Grandense de Letras, da Faculdade de Filosofia de Porto

\begin{tabular}{|l|c|c|c|c|}
\hline \multicolumn{1}{|c|}{ Atividade profissional/ocupacional } & $\begin{array}{c}\text { Ingresso } \\
1901(25)\end{array}$ & $\begin{array}{c}\text { Ingresso } \\
1903-1926(30)\end{array}$ & $\begin{array}{c}\text { Ingresso } \\
1933-1962(30)\end{array}$ & $\begin{array}{c}\text { Ingresso } \\
1950-1970(27)\end{array}$ \\
\hline $\begin{array}{l}\text { Detentor de mandato parlamentar ou } \\
\text { cargo político de 10 escalão }\end{array}$ & 19 & 23 & 12 & 8 \\
\hline $\begin{array}{l}\text { Exercício de cargo burocrático } \\
\text { c/pressuposto tútulo escolar de bacharel } \\
\text { e nomeação política sem concurso } \\
\text { público }\end{array}$ & 24 & 18 & 8 & 3 \\
\hline $\begin{array}{l}\text { Exercício de cargo burocrático de } \\
\text { confiança c/ pressuposto de título } \\
\text { escolar e concurso público, mas com } \\
\text { indicação política }\end{array}$ & - & - & 4 & 13 \\
\hline Só Advogado & - & - & 4 & 13 \\
\hline Exercício do Jornalismo & 10 & 8 & 3 & 1 \\
\hline
\end{tabular}

Alegre, da Pontifícia Universidade Católica, da Escola Superior do Comércio que originou a Faculdade de Economia da UFRGS; bem como a forte presença na fundação e direção de jornais como "A Federação", "Jornal do Comércio", além de colégios tradicionais como o "Anchieta", "Sevigné", entre outros.

Confrontando-se os dados trazidos pelos estudos citados (ADORNO, LEITE e FRANCO, GRIJÓ), com indicadores de inserção social trabalhados sobre as informações disponibilizadas por BRAGA, pode-se tentar esboçar um padrão de inserção profissional/ocupacional que permita orientar uma investigação mais profunda referente a trajetória do corpo docente da Faculdade de Direito de Porto Alegre. O quadro a seguir está organizado com base no intervalo de ingresso dos agentes no corpo docente da Faculdade e as atividades exercidas simultaneamente, além da atividade docente, ao longo de sua trajetória de vida: 


\begin{tabular}{|l|c|c|c|c|}
\hline $\begin{array}{c}\text { Atividade } \\
\text { profissional/ocupacional }\end{array}$ & $\begin{array}{c}\text { Ingresso } \\
\text { 1901 (25) }\end{array}$ & $\begin{array}{c}\text { Ingresso } \\
1903-1926(30)\end{array}$ & $\begin{array}{c}\text { Ingresso } \\
1933 / 1962(30)\end{array}$ & $\begin{array}{c}\text { Ingresso } \\
1950-1970(27)\end{array}$ \\
\hline $\begin{array}{l}\text { Participação em } \\
\text { sociedades culturais }\end{array}$ & 3 & 5 & 5 & 3 \\
\hline $\begin{array}{l}\text { Participação em } \\
\text { Associação Corporativa }\end{array}$ & - & 3 & 9 & 11 \\
\hline $\begin{array}{l}\text { Produção intelectual } \\
\text { geral }\end{array}$ & 5 & 6 & 1 & 4 \\
\hline $\begin{array}{l}\text { Produção intelectual } \\
\text { específica jurídica }\end{array}$ & 6 & 5 & 19 & 14 \\
\hline
\end{tabular}

possa somar na elucidação dessa nova rea lidade que se apresenta a todos os bacharéis em direito e, principalmente, aos profissionais ligados a seu ensino.

\section{Bibliografia consultada}

ADORNO, Sérgio. Os Aprendizes do Poder: O bacharelismo liberal na Politica Brasileira. Rio de Janeiro: Paz e Terra, 1988.

ARRUDA JR., Edmundo L. Advogado e Merca do de Trabalho: Um ensaio sobre a crise de identidade sócio-profissional dos bacharéis em direito no Brasil. Campinas/São Paulo: Julex, 1988.

BADIE, B. \& HERMET, G. Política Comparada México: FCE, 1993.

BARRETO, Vicente. O Estado de Direito e os cursos jurídicos: debate original. In BASTOS Aurélio Wender et al. Os Cursos Jurídicos e as elites políticas brasileiras: ensaios sobre a criação dos cursos jurídicos. Brasília: Câmara dos Deputados, 1978.

BENDIX, R. Construção Nacional e Cidadania. São Paulo: EDUSP, 1996.

BIANCO, Feldman B. (org.). Antropologia nas Sociedades Contemporâneas - Métodos. São Paulo: Global, 1987.

BODIGUEL, J-L. Histoire sociale et science politique; Les élites contemporaines. In CHARLE, C. (dir.). Histoire Sociale, Histoire Globale ? Actes du Colloque des 27-28 janvier 1989. Paris, Éd de la Maison des Sciences de l'Homme, 1993.

BOURDIEU, P. Espace Social et genése des "classes". In Actes du la Recherche en Sciences Sociales, juin/1984. pp. 3-12.

BOURDIEU, P. La Noblesse d'état; (Grandes écoles et esprit de corps). Paris: Minuit, 1989.

BOURDIEU, P. Le Capital Social notes provisoires. In Actes du la Recherche en Sciences Sociales, jun/1980.
BOURDIEU, P. La force du Droit: Eléments pour une sociologie du champ juridique. In Actes du la recheche en Sciences Sociales. n. 64, ept. 196. 1985.

BOURDIEU, P. Lilusion Biogrhaphique. In Actes du la Recherche en Sciences Sociales (62/63), 1986.

BRAGA, A. Faculdade de Direito: Subsídios para sua história. Porto Alegre: Fac. Direito UFRGS(mimeo), vols. 1, 2, 3.

CARVALHO, J.M.C. A Construção da Ordem: A elite política imperial. 2, ed. Rio de Janeiro: UFRJ/1996.

CHARLE, C. Pour une histoire sociale des professions juridiques a l'époque contemporaine: Notes pour une recherche. In Actes de la Recheche en Sciences Sociales (76/ 77), mars/1989.

CHARLE, C. Les Elites de la République 1880. 1900. Paris: Fayard, 1987.

CORADINI, O L. Grandes Famílias e Elite profissional na medicina no Brasil. Cadernos de ciência política nำ2. Porto Alegre, 1995.

CORADINI, O L. A Formação da Elite Médica no Brasil e seu recrutamento: confronto como caso francês. Cadernos de ciência política $\mathrm{n}^{\mathrm{o}}$ 11. Porto Alegre, 1998.

DEZALAY, Y., SARAT, A., e SILBEY, S. D'une démarche contestataire à un savoir méritocratique: Esquisse d'une histoire sociale de la sociologie juridique américaine. In Actes du la Recherche en sciences sociales $n^{0} 78$, juin/ 1989.

GRIJÓ, Luiz Alberto. Origens sociais, estratégias de ascensão e recursos dos componentes da chamada "geração de 1907" (dissertação de mestrado). Porto Alegre: PPGCP-UFRGS, set/1998.

GRYNSZPAN, M. Os idiomas da patronagem: Um estudo da trajetória de Tenório Cavalcanti. In Revista Brasileira de Ciências Sociais, $\mathrm{n}^{\circ}$ 14, out/1990, pp. 73-90. fundado em 1926, a AMPRGS (Associação $\quad$ e precisam ser investigadas acuradamente. do Ministério Público do Rio Grande do Espera-se que esta proposta de pesquisa 
LACROIX, B. Ordre politique et ordre social objectivisme, objectivaction et analyse politique. In GRAWITZ, M. et LECA, J. (dir). Trait de Science Politique, vol 1. La science politique, science sociale, l'ordre politique. Paris: PUF 1985.

LACROIX, B. Le politiste et l' analyse des institutions: Comment parler de la présidence de la République. In LACROIX B.\& LAGROYE, J. Le président de la République Usages et genèses d'une institution. Presses de la fondation nationale des Sciences politiques, 1992

LANDE, C.H. Introduction: the dyadic politics: notes for a theory. In SCHMIDT, S. W. et al(eds) Friends, Followers and Factions; A reader in political clientelism. Berkley, University of California Press, 1977.

LEITE, D. B. C. e FRANCO, M. E. D. Faculda de de Direito de Porto Alegre (1900-1936) In Grupo de Estudos sobre Universidade. Reprodução e Recriação Social na Universidade e as ingerências do Estado: o caso da UFRGS. Porto Alegre, jan/1992.
MICELI, S. Intelectuais e Classe dirigente no Bra sil (1920-1945). São Paulo: Difel, 1979.

NEQUETE, L. (org). O Poder Judiciário no Rio Grande do Sul. Livro Comemorativo do centenário do Tribunal, a Relação de Porto Alegre e Tribunal e Justiça do Estado, Ed. TJ, 1974.

PÉCAUT, D. Os Intelectuais a Política no Brasil entre o povo e a nação. São Paulo: Ática, 1990.

SAINT MARTIN, M. Les Reconversions: Le exemple de la noblesse. In Les Élites: Formation, reconversion, internationalisation: Colloque Stockolm, sept/1993.

SOUTO, C. \& FALCÃO, J. Sociologia e Direito São Paulo: Pioneira, 1980.

VÊNANCIO FILHO, A. Das Arcadas ao Bacharelismo (150 Anos de Ensino jurídico no Brasil). 2. ed., São Paulo: Perspectiva, 1982.

VIANNA, L.W. et al. Corpo e Alma da Magis tratura Brasileira. 2. ed., Rio de Janeiro: Revan, 1997.

\section{Como Pesquisar?}

\section{Plaxniet Christiane Z2itschere}

Doutora pela Universidade de Hamburgo, Alemanha; Professora Visitante na Faculdade de Direito da UFRGS pelo programa CAPES/DAAD, março 1998 - maio 1999.

\begin{tabular}{|c|}
\hline 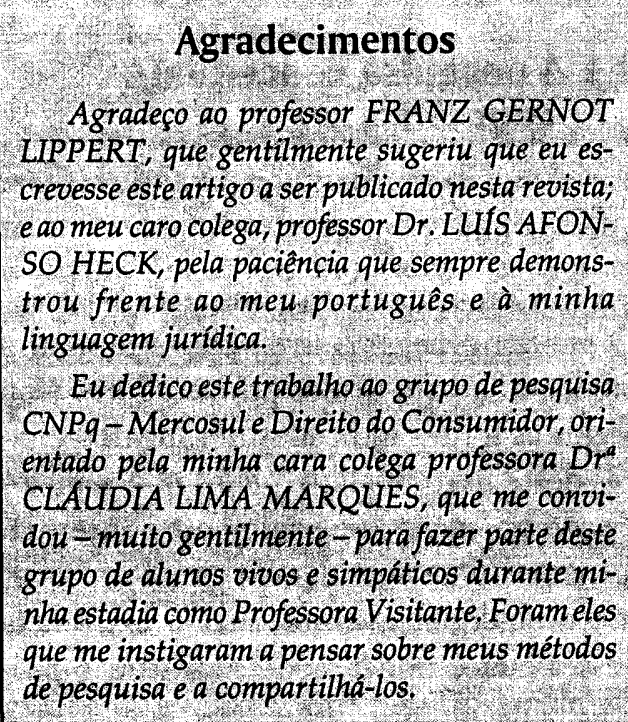 \\
\hline
\end{tabular}

(1) alestra para alunos de graduação e pós-graduação, realizada no dia 22.04.1999, na Faculdade de Direito da UFRGS, denominada: "Como pesquisar e navegar na pesquisa: uma introdução ao método alemão".

\section{Nota preliminar}

Este artigo destina-se, especialmente, aos alunos que começam a desenvolver o processo de pesquisa. Mas, talvez, seja também, em parte, interessante para os colegas professores, devido à cultura jurídica diferente na qual se formou a autora, oferecendo, desse modo, possivelmente, não só um outro enfoque sobre o tema, mas também idéias 'complementares para as orientações dos seus jovens pesquisadores.

\section{A questão da curiosidade e} o tema

Toda a pesquisa tem como base um interesse de buscar - ou uma visão da realidade jurídica ou uma explicação para essa 